\title{
Calcium and Vitamin D Supplementation and Loss of Bone Mineral Density in Women Undergoing Breast Cancer Therapy
}

\author{
Mridul Datta ${ }^{1}$ and Gary G. Schwartz ${ }^{2}$ \\ ${ }^{1}$ Department of Social Sciences and Health Policy, Wake Forest School of Medicine, Winston- \\ Salem, NC, U.S.A \\ ${ }^{2}$ Departments of Cancer Biology, Urology, and Epidemiology and Prevention, Wake Forest \\ School of Medicine, Winston-Salem, NC, U.S.A
}

\begin{abstract}
An unintended consequence of breast cancer therapies is an increased risk of osteoporosis due to accelerated bone loss. We conducted a systematic review of calcium and/or vitamin $\mathrm{D}(\mathrm{Ca} \pm \mathrm{D})$ supplementation trials for maintaining bone mineral density (BMD) in women with breast cancer using the "before-after" data from the $\mathrm{Ca} \pm \mathrm{D}$ supplemented comparison group of trials evaluating the effect of drugs such as bisphosphonates on BMD. Whether $\mathrm{Ca} \pm \mathrm{D}$ supplements increase BMD in women undergoing breast cancer therapy has never been tested against an unsupplemented control group. However, results from 16 trials indicate that the $\mathrm{Ca} \pm \mathrm{D}$ doses tested (500-1500 mg calcium; 200-1000 IU vitamin D) were inadequate to prevent BMD loss in these women. Cardiovascular disease is the main cause of mortality in women with breast cancer. Because calcium supplements may increase cardiovascular disease risk, future trials should evaluate the safety and efficacy of $\mathrm{Ca} \pm \mathrm{D}$ supplementation in women undergoing breast cancer therapy.
\end{abstract}

\section{Keywords}

breast cancer; calcium; vitamin D; osteoporosis; bone mineral density

\section{Introduction}

Osteoporosis is a significant health concern in postmenopausal women, especially women with breast cancer. Breast cancer therapies that reduce estrogen levels (e.g. oophorectomy, chemotherapy, aromatase inhibitors (AI)), increase bone resorption without a corresponding increase in bone formation [1, 2] resulting in loss of bone mineral density (BMD) [1, 3]. Compared to healthy postmenopausal women who may lose $\sim 1 \%$ BMD per year, women with breast cancer lose 2-3 fold more BMD [1] increasing the risk of fractures, including fractures at an earlier age $[4,5]$. Hip and vertebral fractures are associated with significant declines in function, in health-related quality of life (HRQOL) [5-8], and in higher mortality

\footnotetext{
(c) 2013 Elsevier Ireland Ltd. All rights reserved.

Contact Details of Corresponding Author: Dr. Gary G. Schwartz, Departments of Cancer Biology, Urology, and Epidemiology and Prevention, Wake Forest School of Medicine, Medical Center Blvd., Winston-Salem, NC 27157, U.S.A., Phone: +13367167446, Fax: +13367165687, gschwart@wakehealth.edu.

Conflict of Interest

The authors have declared no conflicts of interest.

Publisher's Disclaimer: This is a PDF file of an unedited manuscript that has been accepted for publication. As a service to our customers we are providing this early version of the manuscript. The manuscript will undergo copyediting, typesetting, and review of the resulting proof before it is published in its final citable form. Please note that during the production process errors may be discovered which could affect the content, and all legal disclaimers that apply to the journal pertain.
} 
rates $[9,10]$. Consequently, management of accelerated bone loss in women with breast cancer is a pressing oncologic need. We recently reviewed evidence indicating that 500-1000 mg supplemental calcium and 200-500 IU vitamin D/day were ineffective in preventing loss of BMD in men undergoing androgen deprivation therapy for prostate cancer [11]. Here we evaluated the effectiveness of supplemental calcium and/or vitamin D $(\mathrm{Ca} \pm \mathrm{D})$ in preventing bone loss in women undergoing treatment for breast cancer.

\section{Calcium and vitamin $D$ intake among women}

The dietary reference intakes of nutrients for Americans are established by the Institute of Medicine (IOM) which recommends a daily intake of $1000 \mathrm{mg}$ and $1200 \mathrm{mg}$ calcium for women between $19-50$ and $>51$ years, respectively. The recommended vitamin D intake for women $<70$ and $>70$ years is 600 and 800 IU/day [12]. The tolerable Upper Limit [UL], the level below which a nutrient can be consumed without adverse effects, for calcium in women between $19-50$ years is $2500 \mathrm{mg}$ and is $2000 \mathrm{mg}$ for women $\geq 51$ years. Calcium intake above the UL may cause constipation, hypercalciuria, hypercalcemia, vascular and soft tissue calcification and nephrolithiasis. The UL for vitamin D in women $\geq 19$ years is 4000 IU/day [12]. Excessive intake of vitamin D may cause higher fall and fracture risk, hypercalciuria, hypercalcemia, and higher all-cause mortality [13].

Data on the nutritional status of the US population is gathered by the National Health and Nutrition Examination Survey (NHANES) [14]. Based on the 2003-2006 NHANES, total calcium intake (diet+supplements) for women between 31-50, 51-70 and 270 years was $1055 \mathrm{mg}, 1186 \mathrm{mg}$ and $1139 \mathrm{mg}$ respectively [15]. The mean vitamin D intake for women 251 years ranged between 156-180 IU/day (3.9-4.5 $\mu \mathrm{g} /$ day), but the estimated total daily vitamin D intake was $400 \mathrm{IU}(10 \mu \mathrm{g})$ [15].

\section{Calcium Physiology}

The adult human body contains approximately $1 \mathrm{~kg}$ of calcium, of which more than $99 \%$ is stored in the bone and teeth. Longitudinal studies have shown that calcium intake is a minor but significant predictor of total bone mass in adults. Data from NHANES indicate that Caucasian women with low milk intake during childhood and adolescence had low BMD during adulthood and a higher risk of fracture [16]. Although a protective effect of youthful calcium intake on fracture risk in adulthood is established, whether there is a protective effect of calcium intake in adulthood on fracture risk is controversial [17, 18]. Thus, in their recent review, the US Preventive Services Task Force (USPSTF) concluded that there was insufficient evidence to assess the risk/benefit ratio for supplementing pre-menopausal women with $\geq 400 \mathrm{IU}$ vitamin D3 and 1,000 $\mathrm{mg}$ calcium for the primary prevention of fractures. The USPSTF recommended against daily supplementation of $\leq 400$ IU vitamin D3 and 1,000 $\mathrm{mg}$ of calcium for the primary prevention of fractures in non-institutionalized postmenopausal women, citing an increased risk of renal stones as a possible harm [19].

Calcium intake, unless extremely low or extremely high, does not influence the levels of total serum calcium in blood [20]. Serum calcium levels influence vital physiologic processes such as heart rate and nerve conduction and therefore are under tight physiologic control. The skeleton is the reservoir for calcium in blood. When levels of ionized calcium in serum drop below their set point, the calcium-sensing receptor on the parathyroid glands signals parathyroid cells to manufacture and release parathyroid hormone (PTH) into the circulation. PTH acts to conserve calcium by driving the conversion of 25-hydroxyvitamin D (25-OHD) to 1, 25-dihydroxyvitamin D (1,25(OH)2D) in the kidney; reducing calcium excretion in the urine, and by liberating calcium from the skeleton into the circulation. The resulting increase in ionized calcium in blood restores calcium balance and inhibits further release of PTH [21]. Vitamin D deficiency, which is common among many women with 
breast cancer, results in elevated levels of serum PTH (secondary hyperparathyroidism) and acts to weaken bone [22].

\section{Treatment options for breast cancer}

Breast cancer is a heterogeneous group of diseases with distinct clinical, morphological and molecular phenotypes[23]. Its treatment depends upon molecular subtype and hormone receptor status (e.g., estrogen and/or progesterone receptors)[24]. Hormonal therapies for premenopausal women include selective estrogen receptor modulators (SERMs) or ovarian suppression/ablation[24]. Tamoxifen, a SERM, is the standard for premenopausal women with or without chemotherapy[24]. Ovarian suppression/ablation is accomplished, surgically or medically[24]. Chemotherapies include anthracyclines (e.g., doxorubicin), alkylating agents (e.g., cyclophosphamide), antimicrotubule agents (e.g., docetaxel), and targeted therapies include monoclonal antibody-based tyrosine kinase inhibitors (e.g, bevacizumab). Some chemotherapies (e.g. anthracyclines) may cause ovarian toxicity leading to premature menopause [24]. Standard endocrine therapy in postmenopausal women with ER+ breast cancer includes tamoxifen, tamoxifen followed by AI and/or AI alone [25].

\section{Role of estrogen in breast cancer and bone loss}

Estradiol (E2) and estrone (E1) are the dominant circulating estrogens before and after menopause, respectively [26, 27]. The ovaries maintain circulating estrogen levels in premenopausal women, but as ovarian estrogen synthesis decreases post- menopause, estrogen is produced peripherally by the aromatization of androgens [28] by cytochrome P450 aromatase monooxygenase enzymes that are expressed in the ovaries, placenta, adipose tissue, skin, chondrocytes and osteoblasts [27, 29]. Because osteoclasts are inhibited by estrogen estrogen deficiency is associated with loss of BMD and increased fracture risk [27].

Tamoxifen shows both estrogen-agonist and antagonist effects [30, 31]. Premenopausal women with breast cancer undergoing tamoxifen therapy lose BMD because tamoxifen antagonizes the activity of estrogen [32]. For example, pre-menopausal women treated with tamoxifen lost $4.6 \% \mathrm{BMD}$ at the lumbar spine $v s$. a gain of $0.6 \%$ in the tamoxifen untreated group [33]. Additionally, ovarian ablation therapies (e.g. LHRH agonists) accelerate bone loss to 2-3 times the rate observed in healthy postmenopausal women [1]. Aromatase inhibition prevents the conversion of androgens to estrone, lowering circulating and tissue estrogen levels and increasing fracture risk [34]. (See Hadji et al. [35] for a review of BMD loss in premenopausal women undergoing various breast-cancer treatments.)

AIs are more effective than tamoxifen in treating postmenopausal ER+ breast cancer, and are increasingly being used as first line therapy [36]. However, AIs are associated with a significant loss of BMD and a higher fracture rate than tamoxifen [37-39]. In the prospective substudy of the Anastrozole, Tamoxifen, Alone or in Combination (ATAC) trial $(\mathrm{n}=308)$, median BMD loss at the lumbar spine and hip after 2 years of AI-anastrozole were $4.1 \%$ and $3.9 \%$ respectively compared to an increase of $2.2 \%$ and $1.2 \%$ in the tamoxifen treated group [40]. In the Breast International Group (BIG) 1-98 trial, women treated with the AI letrozole $(\mathrm{n}=2448)$ had a higher incidence of bone fractures $(9.3 \%)$ vs. women treated with tamoxifen $(\mathrm{n}=2447 ; 6.5 \%)$ [39].

\section{Review of clinical practice guidelines}

We reviewed clinical practice guidelines for bone health in women with breast cancer by searching the websites of professional organizations including the National Comprehensive Cancer Network (NCCN) [25], the American Society of Clinical Oncology (ASCO) [41], 
and the National Guidelines Clearinghouse [42]. For example, to counter treatment-related bone loss, the Belgian Bone Club recommends 400-800 IU vitamin D and supplemental calcium to maintain daily calcium intake between $1200-1500 \mathrm{mg}$ [43]. ASCO [44] recommends daily intake of $1200 \mathrm{mg}$ calcium and 400-600 IU vitamin D. The European Society for Clinical and Economical Aspects of Osteoporosis and Osteoarthritis (ESCEO) recommends calcium intake of at least $1000 \mathrm{mg} /$ day with $>800 \mathrm{IU} /$ day or 10,000 IU/week of vitamin D [45]. A United Kingdom Expert group [46] recommends $\geq 1000 \mathrm{mg}$ calcium and 400-800 IU vitamin D for premenopausal women who experience premature menopause from breast cancer treatment and postmenopausal women with breast cancer who have a Tscore between -1 and $-2[46]$. The NCCN recommends that younger women at risk for developing cancer treatment-induced bone loss and women $>50$ years consume $1200 \mathrm{mg}$ total calcium and 800-1000 IU vitamin D/day [25]. An international expert group recommends $1300 \mathrm{mg}$ calcium and 800-2000 IU vitamin D daily for all women undergoing AI therapy [47].

We also searched the internet informally for recommendations proffered by patient support organizations using the names of breast cancer support organizations and the terms "calcium," "vitamin D," "breast cancer," and "recommendations." Thus, Breastcancer.org recommends total calcium intake of $1200 \mathrm{mg}$ calcium/day for women > 50 years and $400 \mathrm{IU}$ vitamin D/day for women 50-70 years and $600 \mathrm{IU}$ for women > 70 years [48]. Living Beyond Breast Cancer reports common physician recommendations of 1000-1500 mg calcium and 400-1000 IU vitamin D/day [49]. Neither the Susan G. Komen for the Cure [50] nor the Young Survival Coalition [51] specified quantities of $\mathrm{Ca} \pm \mathrm{D}$.

\section{Clinical trial evidence}

We evaluated clinical trial evidence for calcium and vitamin D supplementation in maintaining skeletal health of women with breast cancer. We searched PUBMED for publications in English during 1990-2012 using the MeSH terms "clinical trial", "breast neoplasm", "osteoporosis", "calcium", "calcium, dietary", "vitamin D", "25-hydroxyvitamin D". We excluded drug trials (eg. bisphosphonates) that did not include a comparison group $[52,53]$ or those that simultaneously gave antiresorptive drugs to women in the comparison group along with $\mathrm{Ca} \pm \mathrm{D}[54]$.

\subsection{Calcium and/or vitamin $D$ supplement trials among premenopausal women}

We found no trials that evaluated $\mathrm{C} \pm \pm \mathrm{D}$ supplements $v s$. no supplements on BMD in premenopausal women with breast cancer. We retrieved seven trials (see Table 1) that evaluated antiresportive drugs (e.g., bisphosphonates) on BMD and used the "before-after" data from the comparison group to assess change in BMD. We excluded one trial due to small sample size $(\mathrm{n}=11)$ [55].

Kim et al.[56] evaluated early vs. delayed zoledronic acid on loss of BMD in women undergoing adjuvant chemotherapy $(n=112)$. Because none of the participants in the delayed zoledronic acid group received zoledronic acid during the study period, the "delayed" group served as our comparison group. All participants received $500 \mathrm{mg}$ calcium and $1000 \mathrm{IU}$ vitamin D/day. After 12 months, the comparison group lost 7.5\% $\pm 2.8(\mathrm{SD}) \mathrm{BMD}$ at the lumbar spine and 3.4\% \pm 3.3 at the femoral neck. Shapiro et al.[57] studied change in BMD at the lumbar spine in 439 women with chemotherapy-induced ovarian failure in the CALGB Trial 79809 with early (within 1-3 months of starting chemotherapy) vs. delayed (12-14 months after chemotherapy) zoledronic acid. Participants were instructed to consume at least $1000 \mathrm{mg}$ calcium and $400 \mathrm{IU}$ vitamin $\mathrm{D} /$ day. After 12 months, the delayed group $(\mathrm{n}=80)$ lost $6.7 \%$ (range $-2.9--9.7 \%$ ) BMD at the lumbar spine. 
Hershman et al.[58] randomized 113 women with newly-diagnosed non-metastatic breast cancer scheduled to begin chemotherapy to zoledronic acid or placebo. All participants received $1000 \mathrm{mg}$ calcium and 400-800 IU vitamin D supplements/day. After 12 months, the placebo group lost BMD at the lumbar spine (4.39\% \pm 0.45 (SEM)), femoral neck $(1.5 \%$ $\pm 0.56)$ and total hip $(2.08 \% \pm 0.36)$. Hershman et al.[59] followed this cohort for an additional 12 months after the last dose of zoledronic acid. Participants received $1000 \mathrm{mg}$ calcium and $400 \mathrm{IU}$ vitamin $\mathrm{D} /$ day. Compared to baseline, the placebo group $(\mathrm{n}=30)$ continued to lose BMD at the lumbar spine (5.4\% \pm 0.55 (SEM), 6.3\% \pm 0.83 ), femoral neck $(1.5 \% \pm 0.61,2.4 \% \pm 0.71)$ and total hip $(1.9 \% \pm 0.66,2.6 \% \pm 0.84)$ after 12 and 24 months, respectively. Hines et al.[60] evaluated the effect of chemotherapy on BMD with or without risedronate $(\mathrm{n}=216)$. All participants received $600 \mathrm{mg}$ calcium and $400 \mathrm{IU}$ vitamin $\mathrm{D}$ and were randomized to $35 \mathrm{mg}$ risedronate or placebo. Placebo group participants lost 5.4\% BMD at the lumbar spine (95\% CI: -6.76 - -3.98), 3.4\% (95\% CI: $-4.43--2.28)$ at the hip, and $2.4 \%$ (95\% CI: $-5.15-0.27$ ) at the femoral neck. Fuleihan et al.[61] randomized 40 women with newly diagnosed non-metastatic breast cancer undergoing chemotherapy to IV pamidronate in $500 \mathrm{ml}$ dextrose in water or placebo (500 $\mathrm{ml}$ dextrose in water). Participants were advised to take $500 \mathrm{mg}$ calcium and $400 \mathrm{IU}$ vitamin D supplements/day. After 12 months, the placebo group lost $3.2 \% \pm 5.0(\mathrm{SD}) \mathrm{BMD}$ at the lumbar spine and $2.8 \% \pm 4.0$ at the total hip.

\subsection{Calcium and/or vitamin D supplement trials among postmenopausal women}

We found no trials comparing $\mathrm{Ca} \pm \mathrm{D}$ supplements $v s$. no supplements in postmenopausal women. We identified 10 trials with "before-after" data on BMD (see Table 1). In women scheduled to begin AI therapy, Prieto-Alhambra et al.[62] evaluated vitamin D supplementation and bone loss in normal or osteopenic women not treated with bisphosphonates. All women received $1000 \mathrm{mg}$ calcium and $800 \mathrm{IU}$ vitamin D. Women with baseline vitamin $\mathrm{D}$ levels $<30 \mathrm{ng} / \mathrm{ml}$ additionally received $16,000 \mathrm{IU}$ vitamin $\mathrm{D}_{3}$ every 2 weeks. After 12 months women lost 0.72\% BMD at the hip (95\% CI: $-1.19--0.02), 1.49 \%$ at the femoral neck (95\% CI: $-2.44--0.55)$ and $1.68 \%$ at the lumbar spine (95\% CI: -2.20 -1.15). After 3 months of supplementation, each $10 \mathrm{ng} / \mathrm{ml}$ increase in vitamin D resulted in a $0.5 \%$ (95\% CI: 0.26-0.75) lower BMD loss at the lumbar spine. Additionally, women with serum vitamin D levels $>40 \mathrm{ng} / \mathrm{ml}$ had 1.7\% (95\% CI:0.4-3.0) lower BMD loss at the lumbar spine. Sergi et al.[63] evaluated the effect of anastrazole (AI) alone or with risedronate on BMD in 51 women with hormone receptor-positive (HR+) breast cancer. Participants received $1000 \mathrm{mg}$ calcium carbonate and $800 \mathrm{IU}$ vitamin D/day. After 24 months, the anastrozole and $\mathrm{Ca}+\mathrm{D}$ group lost BMD at the lumbar spine (3\%), trochanter $(4.0 \%)$ and the femoral neck $(4.1 \%)$. Safra et al.[64] studied the percent change in BMD at the lumbar spine in 90 women treated with tamoxifen followed by letrozole with or without zoledronic acid. All women received $1200 \mathrm{mg}$ calcium and $400 \mathrm{IU}$ vitamin D/day. Women receiving letrozole only lost $5.89 \%$ and $6.51 \%$ BMD at the lumbar spine after 12 and 24 months of treatment.

Rastelli et al.[65] evaluated the effects of high dose vitamin D on AI-induced musculoskeletal symptoms and bone loss in 60 women with HR+ invasive, nonmetastasized breast cancer. Women were stratified based on serum 25-hydroxyvitamin D levels. Women with $25-\mathrm{OHD}$ between $20-29 \mathrm{ng} / \mathrm{ml}$ received 50,000 IU vitamin $\mathrm{D}_{2}$ once a week for 8 weeks and then monthly, whereas women with 25-OHD between 10-19 ng/ml received 50,000 IU vitamin $\mathrm{D}_{2}$ once a week for 16 weeks and then monthly for the duration of the study. After 6 months, the placebo group lost $0.36 \% \pm 0.75$ (SEM) BMD at the lumbar spine and $1.39 \% \pm 0.66$ at the femoral neck, but gained $0.04 \% \pm 0.63 \mathrm{BMD}$ at the total femur, whereas women in the vitamin $\mathrm{D}$ group gained $\mathrm{BMD}$ at the lumbar spine $(0.12 \pm 0.82)$ and femoral neck $(0.45 \pm 0.72)$ but lost BMD at the total femoral $(-0.005 \% \pm 0.69)$. 
Markopoulos et al. [66] evaluated risedronate and BMD change at the hip and lumbar spine in 213 women with $\mathrm{HR}+$ breast cancer scheduled to receive anastrozole. Women were randomized to anastrozole alone or with risedronate based on their T-score. All women received $1000 \mathrm{mg}$ calcium and $400 \mathrm{IU}$ vitamin D supplements/day. After 12 and 24 months, median BMD loss in the anastrozole only groups with a T-score $\geq-1$ was $5.3 \%$ and $2.5 \%$ at the lumbar spine and $2.4 \%$ and $5.7 \%$ at the hip. Women on anastrozole with T-scores $-2<\mathrm{T}<-1$, lost $0,1.5 \%$ BMD at the lumbar spine and 1.3 and $3.9 \%$ at the hip.

Van Poznak et al.[67] evaluated change in BMD at the lumbar spine and total hip in 234 women with $\mathrm{HR}+$ breast cancer at the end of 12 and 24 months with anastrozole alone, with placebo or with risedronate. Participants were allocated to these groups based on fracture risk. High fracture (anastrazole+risedronate) and low fracture-risk (anastrozole alone) groups were open-label and without a comparison group, whereas women in the moderaterisk group were randomized in a double-blind manner to receive anastrozole with a placebo or with risedronate. All women received $1000 \mathrm{mg}$ elemental calcium and $400 \mathrm{IU}$ vitamin D supplements/day. After 12 and 24 months, the anastrozole only group lost 0.6 (95\% CI: $-1.93-0.71$ ) and $2.1 \%$ (95\% CI: $-3.60--0.53$ ) BMD at the lumbar spine and $0.4 \%$ (95\% CI: $-1.37-0.68)$ and $0.4 \%$ (95\% CI: $-2.10-1.26$ ) at the hip. The anastrozole+placebo group lost $1.2 \%$ (95\% CI: $-2.19--0.24)$ and $1.8 \%$ (95\% CI: $-3.25--0.25)$ BMD at the lumbar spine and $0.4 \%$ (95\% CI: $-1.17-0.31)$ and $1.1 \%$ (95\% CI: $-2.14--0.10)$ at the hip after 12 and 24 months.

Ellis et al.[68] evaluated denosumab vs. placebo in maintaining BMD at the lumbar spine in 252 women with HR+ non-metastatic breast cancer undergoing AI therapy. Participants were instructed to consume $1000 \mathrm{mg}$ calcium and $\geq 400 \mathrm{IU}$ vitamin D/day and were stratified based on the duration of AI therapy ( $\leq 6$ months or $>6$ months). After 24 months, the placebo group lost $\sim 1.5 \% \mathrm{BMD}$ at the lumbar spine. Women on $\mathrm{AI} \leq 6$ months lost $\sim 1 \%$ $\mathrm{BMD}$ and women on $\mathrm{AI}>6$ months lost $\sim 1.5 \% \mathrm{BMD}$ at the lumbar spine.

Greenspan et al. [69] evaluated change in spine and hip BMD with or without risedronate in 87 women who underwent breast cancer chemotherapy with or without tamoxifen or AI. Dietary calcium was assessed by questionnaire. Women consuming $<1200 \mathrm{mg}$ calcium/day were supplemented with $500 \mathrm{mg}$ calcium carbonate and $200 \mathrm{IU}$ vitamin D. The number of participants that received calcium and vitamin D supplements was not specified. The mean dietary calcium intake among the placebo group at baseline was $691 \pm 347 \mathrm{mg}$. After 24 months, the placebo group prescribed AIs lost BMD at the spine (4.8\% $\pm 0.8(\mathrm{SE}))$, lateral spine $(5.2 \% \pm 1.6)$, hip $(2.8 \% \pm 0.5)$, trochanter $(4.2 \% \pm 0.7)$, femoral neck $(2.4 \% \pm 1.1)$, onethird distal radius $(2.1 \% \pm 0.6)$ and at the total radius $(3 \% \pm 0.3)$. The placebo group with no AI lost BMD at all sites except the spine, where a gain of $0.5 \% \pm 0.9$ was observed.

Lester et al.[70] evaluated ibandronate vs. placebo on BMD in 131 women with ER+ breast cancer taking anastrozole. Participants received $500 \mathrm{mg}$ calcium and $400 \mathrm{IU}$ vitamin D/day. After 12 and 24 months, the placebo group lost 2.35\% and 3.22\% BMD at the lumbar spine and $2.27 \%$ and $3.90 \%$ at the total hip, respectively. Sawka et al.[71] compared cyclic etidronate or alendronate vs. calcium and vitamin D (control group) in improving lumbar spine BMD after one year in 70 women. All participants were advised to consume 800-1000 IU vitamin D and $1500 \mathrm{mg}$ elemental calcium (diet+supplements)/day. After 12 months, the control group (calcium+vitamin D only; $\mathrm{n}=16$ ) lost 1.4\% $\pm 3.8(\mathrm{SD})$ and 1.7\% $\pm 3.7 \mathrm{BMD}$ at the lumbar spine and femoral neck, respectively.

In summary, the results from 16 trials (see Table 1) indicate that 500-1500 mg calcium and 200-1000 IU vitamin D is inadequate to prevent loss of BMD in women with breast cancer. Despite supplementation, women lost BMD at virtually every site in every study (see Figure 
1). Although it is possible that supplementation had some effect in reducing loss of BMD (i.e., BMD loss may have been greater in unsupplemented women), the lack of an unsupplemented comparison group does not permit a conclusion regarding the effects of supplementation per se.

\section{Nonskeletal disease outcomes in breast cancer and with calcium and vitamin D supplementation}

Because $\mathrm{C} a \mathrm{D}$ did not show a benefit in preserving BMD in women undergoing treatment for breast cancer, we evaluated potential non-skeletal risks associated with $\mathrm{Ca} \pm \mathrm{D}$ supplementation in these women.

\subsection{Breast cancer and cardiovascular disease}

Coronary artery disease (CAD) is the primary cause of death in older women; half of women over 40 are at risk of developing cardiovascular disease (CVD) in their lifetime [72]. Using the Surveillance, Epidemiology and End Results (SEER) database, Patnaik et al.[73] reported that CVD was the main cause of death in women with breast cancer $(15.9 \%$; $95 \%$ CI: $15.6-16.2 \%)$, followed closely by breast cancer (15.1\%; 95\% CI: 14.8-15.4). Early menopause $(<46$ years) appears to be an independent predictor of heart disease even after adjusting for age, ethnicity, study site (HR=2.11; 95\% CI: 1.19-3.75) and cardiovascular risk factors ( $\mathrm{HR}=2.08$; 95\% CI: 1.17-3.70) [74]. Therapies for breast cancer may exacerbate preexisting cardiovascular risk [75]. For example, some chemotherapies (alkylating agents, anthracyclines) cause left ventricular dysfunction, ischemia (antimetabolites, small molecule tyrosine kinase inhibitors), hypertension (small molecule tyrosine kinase inhibitors), and venous thromboembolisms (alkylating agents, small molecule tyrosine kinase inhibitors) [76]. Additionally, in the Danish Breast Cancer Cooperative Groups study $(\mathrm{n}=16289)$, women $>50$ years, tamoxifen increased the risk of deep vein thrombosis and pulmonary embolism particularly during the first two years of therapy [77]. Although the odds of developing venous thromboembolisms $(\mathrm{OR}=0.55,95 \%$ CI: 0.46-0.64, $\mathrm{p}<0.001)$ and endometrial cancer $(\mathrm{OR}=0.34,95 \% \mathrm{CI}$ : $0.22-0.53$, $\mathrm{p}<0.001)$ decreased, the odds of developing CVD increased with increasing duration of $\mathrm{AI}$ therapy $(\mathrm{OR}=1.26,95 \% \mathrm{CI}$ : $1.10-1.43, \mathrm{p}<0.001)$ [78]. Radiation therapy to the breast is also associated with cardiovascular sequelae, as it can cause CAD, pericarditis, and cardiomyopathy [75].

\subsection{Calcium supplementation and cardiovascular disease}

The relationship between calcium supplementation and CVD is controversial[79]. Numerous studies [80-83] have reported positive associations between calcium supplements and CVD, whereas others have not [79, 84-87]. For example, Manson et al. [85] assessed the association between calcium and vitamin D supplementation and coronary artery calcium in 1064 women who had undergone hysterectomy. Women were randomized to $1000 \mathrm{mg}$ calcium carbonate and 400 IU vitamin D/day or matching placebo. Coronary artery calcium measurements were performed after a mean of 7 years post-treatment. There was no significant difference in coronary artery calcium between the intervention and placebo groups. Because women in this study continued to take their "personal" calcium (up to 1000 $\mathrm{mg}$ ) and vitamin D (up to $600 \mathrm{IU}$ ) supplements, the distinction between treated and "placebo" groups may have been reduced.

Lewis et al.[84] randomized 1460 women to either $600 \mathrm{mg}$ calcium carbonate or identical placebo daily for 5 years. The women were followed for an additional 4.5 years for the time to first hospitalization for atherosclerotic vascular disease and mortality rates. There were no differences in time of first hospitalizations or the risk of death at 5 or 9.5 years. After 9.5 (but not 5) years, significantly fewer deaths from heart failure were observed in the calcium 
supplemented group (age-adjusted odds ratio $(\mathrm{OR})=0.50,95 \% \mathrm{CI}$ : 0.26-0.97). There was no difference in the incidence of MI at 5 or 9.5 years. Among women who had atherosclerosis at baseline and at the end of 5 (but not at 9.5) years, calcium supplements reduced the risk of an atherosclerotic vascular disease event (HR=0.438, 95\% CI: 0. 246-0.781).

Conversely, in a reanalysis of the Women's Health Initiative calcium and vitamin D data, Bolland et al.[80] reported that $\mathrm{Ca} \pm \mathrm{D}$ dose-dependently increased the risk of cardiovascular events, particularly MI (RR=1.24; 95\% CI: 1.07-1.45). Similarly, review of the Heidelberg cohort $(n=23,980)$ of the European Prospective Investigation into Cancer and Nutrition study (EPIC-Heidelberg) [81], indicated that participants who consumed calcium supplements had a significantly higher incidence of MI (HR=2.39; 95\% CI: 1.12-5.12). Bolland et al.[82] conducted a secondary analysis of data from a randomized, placebocontrolled trial in 1471 healthy postmenopausal women to evaluate the effect of calcium supplementation (1000 mg elemental calcium as calcium citrate) on MI, stroke and sudden death. More women in the calcium group had MI's ( 45 events in 31 women; RR=2.24; $95 \%$ CI: 1.20-4.17), stroke and sudden death ( $R R=1.66$; 95\% CI: 1.15-2.40) vs. women in the placebo group.

An increased risk of CVD associated with calcium supplementation is acknowledged in chronic kidney disease [88]. Compared to patients on a calcium-free intervention, patients who received 1.2-2.3 g elemental calcium for the treatment of hyperphosphatemia experienced significantly greater vascular calcification $[89,90]$. The mechanisms involved are believed to be molecular events that promote an osteochondrogenic phenotype. It is credible that these mechanisms would operate in individuals without chronic kidney disease who consume calcium in excess of a neutral calcium balance, which has been estimated at $741 \mathrm{mg} /$ day in healthy individuals [91].

Although the possible risk enhancement for CVD associated with calcium supplementation remains unsettled, a recent review [92] concluded that calcium supplementation offered no benefits in reducing the risk of coronary artery disease or stroke. Thus, it appears that the association between calcium supplements and CVD is either null or is positive (i.e., an increase in risk). If the association is null, then calcium supplementation of women with breast cancer may be benign. However, an increased incidence of kidney stones has been reported with higher calcium intake (>UL), prompting the USPSTF to recommend that healthy postmenopausal women avoid supplements of up to $1000 \mathrm{mg}$ calcium and/or $400 \mathrm{IU}$ vitamin D/day[19]. Conversely, if calcium supplements increase the risk of CVDs, then their continued use in women with breast cancer should be vigorously re-examined.

\section{Discussion}

$\mathrm{Ca} \pm \mathrm{D}$ supplements are widely recommended by lay and professional groups for the prevention and management of osteoporosis in healthy women and in women with breast cancer undergoing treatment. We found no clinical trial evidence comparing $\mathrm{Ca} \pm \mathrm{D}$ supplements vs. no supplements in preventing BMD loss in women with breast cancer. However, results from 16 trials of $\mathrm{Ca} \pm \mathrm{D}$ supplements at doses commonly recommended, indicate that 500-1500 $\mathrm{mg}$ calcium and 200-1000 IU vitamin D/day were inadequate to inhibit bone loss in pre- and postmenopausal women with breast cancer.

Breast cancer treatments, especially AIs result in a significant decrease in BMD. Several Phase III trials (e.g. the BIG 1-98 and ATAC) have evaluated BMD change in women undergoing breast cancer mono- or combination therapy who were not supplemented with calcium and/or vitamin D [37-39]. In the BIG 1-98 trial, postmenopausal women treated with letrozole $(n=2448)$ had a higher incidence of fractures vs. women $(n=2447)$ on tamoxifen $(9.3 \%$ vs $6.5 \%)$ [39]. At the 100 -month follow-up of the ATAC trial, 
postmenopausal women treated with anastrozole $(\mathrm{n}=2618)$ had a higher fracture rate (incidence rate ratio $1.55 ; 95 \%$ CI $1.31-1.83$; $<<0.0001$ ) vs. women treated with tamoxifen $(\mathrm{n}=2598)$ [38].

The trials that we reviewed have numerous methodological limitations. For example, many $[57,60,66,68,70,93]$ did not specify the amount of elemental calcium (the biologically active fraction of dietary calcium) provided or consumed. For example, calcium carbonate and calcium citrate contain $40 \%$ and $21 \%$ elemental calcium, respectively [94]. Moreover, it is impossible to assess total calcium intake in these women without dietary calcium intake data. Assuming an average intake of $\sim 750 \mathrm{mg}$ calcium (based on NHANES, 2003-2006) participants likely consumed 1250 - 2250mg calcium/day. Thus, the calcium intake recommended to maintain BMD in healthy women is inadequate to prevent bone loss in women undergoing therapy for breast cancer [95]. Additionally, vitamin D supplementation is associated with reduced risks for CVD risk and early death [96-99]. Because calcium and vitamin $\mathrm{D}$ were often taken together, we were unable to evaluate the possible beneficial effects of vitamin D alone on BMD. However, results of trials[62, 65] in postmenopausal women indicate that higher vitamin D supplements and serum levels $(40 \mathrm{ng} / \mathrm{ml})$ were associated with reduced loss of BMD in these women $[62,65]$.

Despite evidence demonstrating reduction of BMD loss with 500-1000 mg calcium supplementation in healthy postmenopausal women experiencing "natural" menopause[100-102], similar supplementation studies in women with breast cancer that we reviewed failed to retard BMD loss. How can these results be reconciled? At least one explanation concerns differences in circulating estrogen levels between healthy postmenopausal women and women undergoing treatment for breast cancer. Estrogen deficiency, associated with menopause, is also known to lower intestinal calcium absorption[103]. The mean loss of BMD (-5.58\%) observed in premenopausal women (with drug-induced menopause) (Figure 1) was more than twice that observed in the postmenopausal women $(-2.3 \%)$. The ineffectiveness of $1500 \mathrm{mg}$ calcium and $1000 \mathrm{IU}$ vitamin D observed in these clinical trials suggests that other lifestyle (e.g. exercise) and pharmacologic interventions may be required to prevent loss of BMD in women undergoing treatment for breast cancer.

\section{Conclusion}

$\mathrm{Ca} \pm \mathrm{D}$ supplements are the mainstay of osteoporosis management in women and are commonly recommended to women undergoing treatment for breast cancer. However, at doses currently recommended, supplements of vitamin D (200-1000 IU) and calcium (500-1500 mg)/day failed to prevent loss of BMD in women with breast cancer. Breast cancer therapies increase the risk of CVD [75, 76], the primary cause of death in women with breast cancer [73, 104]. Besides an increased risk of CVD from breast cancer treatments, supplemental calcium intake may also increase the risk of CVD, although this remains controversial $[80,81]$. Clinical trials are urgently needed to evaluate the safety and efficacy of $\mathrm{Ca} \pm \mathrm{D}$ supplementation in women with breast cancer. Key endpoints in these trials should include surrogate markers of bone resorption and cardiovascular disease.

\section{Acknowledgments}

Mridul Datta is supported by the Comprehensive Cancer Center of Wake Forest University Cancer Control Traineeship - NCI/NIH Grant\# R25CA122061 


\section{References}

1. Brown S, Guise T. Cancer-associated bone disease. Curr Osteoporos Rep. 2007; 5:120-27. [PubMed: 17925193]

2. Hadji P. Aromatase inhibitor-associated bone loss in breast cancer patients is distinct from postmenopausal osteoporosis. Crit Rev Oncol Hematol. 2009; 69:73-82. [PubMed: 18757208]

3. Hirbe A, Morgan EA, Uluçkan Ö, Weilbaecher K. Skeletal complications of breast cancer therapies. Clin Cancer Res. 2006; 12:6309s-14s. [PubMed: 17062720]

4. Kanis JA, McCloskey EV, Powles T, Paterson AHG, Ashley S, Spector T. A high incidence of vertebral fracture in women with breast cancer. Br J Cancer. 1999; 79:1179-81. [PubMed: 10098755]

5. Edwards BJ, Raisch DW, Shankaran V, McKoy JM, Gradishar W, Bunta AD, et al. Cancer therapy associated bone loss: Implications for hip fractures in mid-life women with breast cancer. Clin Cancer Res. 2011; 17:560-68. [PubMed: 21288927]

6. Brenneman SK, Barrett-Connor E, Sajjan S, Markson LE, Siris ES. Impact of recent fracture on health-related quality of life in postmenopausal women. J Bone Miner Res. 2006; 21:809-16. [PubMed: 16753011]

7. Hagino H, Nakamura T, Fujiwara S, Oeki M, Okano T, Teshima R. Sequential change in quality of life for patients with incident clinical fractures: A prospective study. Osteoporos Int. 2009; 20:695702. [PubMed: 18836672]

8. Hallberg I, Rosenqvist AM, Kartous L, Löfman O, Wahlström O, Toss G. Health-related quality of life after osteoporotic fractures. Osteoporos Int. 2004; 15:834-41. [PubMed: 15045468]

9. Abrahamsen B, van Staa T, Ariely R, Olson M, Cooper C. Excess mortality following hip fracture: A systematic epidemiological review. Osteoporos Int. 2009; 20:1633-50. [PubMed: 19421703]

10. Panula J, Pihlajamäki H, Mattila VM, Jaatinen P, Vahlberg T, Aarnio P, et al. Mortality and cause of death in hip fracture patients aged 65 or older - a population-based study. BMC Musculoskel Disord. 2011; 12:105-10.

11. Datta M, Schwartz GG. Calcium and vitamin D supplementation during androgen deprivation therapy for prostate cancer: A critical review. Oncologist. 2012; 17:1171-79. [PubMed: 22836449]

12. Ross, AC.; Abrams, SA.; Aloia, JF.; Brannon, PM.; Clinton, SK.; Durazo-Arvizu, RA., et al. Dietary reference intakes for calcium and vitamin D. Washington, DC: National Academy of Sciences; 2010.

13. Institute of Medicine. Dietary reference intakes for calcium and vitamin D. Washington, DC: The National Academies Press; 2011.

14. Centers for Disease Control and Prevention. About the national health and nutrition examination survey. Retrieved October 18, 2011, from http://www.cdc.gov/nchs/nhanes/about_nhanes.htm

15. Bailey RL, Dodd KW, Goldman JA, Gahche JJ, Dwyer JT, Moshfegh AJ, et al. Estimation of total usual calcium and vitamin D intakes in the United States. J Nutr. 2010; 140:817-22. [PubMed: 20181782]

16. Kalkwarf HJ, Khoury JC, Lanphear BP. Milk intake during childhood and adolescence, adult bone density, and osteoporotic fractures in us women. Am J Clin Nutr. 2003; 77:257-65. [PubMed: 12499350]

17. Zhu K, Prince RL. Calcium and bone. Clin Biochem. 2012; 45:936-42. [PubMed: 22609892]

18. Lips P, Bouillon R, Van Schoor NM, Vanderschueren D, Verschueren S, Kuchuk N, et al. Reducing fracture risk with calcium and vitamin D. Clin Endocrinol (Oxf). 2010; 73:277-85. [PubMed: 20796001]

19. Moyer VA. Vitamin D and calcium supplementation to prevent fractures in adults: U.S. Preventive Services Task Force recommendation statement. Ann Intern Med. 201310.7326/0003-4819-158-9-201305070-00603

20. Zahrani AA, Levine MA. Primary hyperparathyroidism. Lancet. 1997; 349:1233-38. [PubMed: 9130957] 
21. Brown, EM. Physiology of calcium homeostasis. In: Bilezikian, JP.; Marcus, R.; Levine, MA., editors. The parathyroids: Basic and clincal concepts. 2. San Diego, CA: Academic Press; 2001. p. 167-82.

22. Mann GB, Kang YC, Brand C, Ebeling PR, Miller JA. Secondary causes of low bone mass in patients with breast cancer: A need for greater vigilance. J Clin Oncol. 2009; 27:3605-10. [PubMed: 19546403]

23. Eroles P, Bosch A, Alejandro Pérez-Fidalgo J, Lluch A. Molecular biology in breast cancer: Intrinsic subtypes and signaling pathways. Cancer Treat Rev. 2012; 38:698-707. [PubMed: 22178455]

24. Puhalla S, Bhattacharya S, Davidson NE. Hormonal therapy in breast cancer: A model disease for the personalization of cancer care. Mol Oncol. 2012; 6:222-36. [PubMed: 22406404]

25. National Comprehensive Cancer Network. Guidelines for treatment of cancer by site: Breast cancer v3.2012. Retrieved October 29, 2012, from http://www.nccn.org/professionals/ physician_gls/f_guidelines.asp\#site

26. Burger HG. Physiology and endocrinology of the menopause. Medicine (Baltimore). 2006; 34:2730.

27. Gruber CJ, Tschugguel W, Schneeberger C, Huber JC. Production and actions of estrogens. N Engl J Med. 2002; 346:340-52. [PubMed: 11821512]

28. Miller WR. Biological rationale for endocrine therapy in breast cancer. Best Pract Res Clin Endocrinol Metab. 2004; 18:1-32. [PubMed: 14687595]

29. Bulun SE, Zeitoun K, Sasano H, Simpson ER. Aromatase in aging women. Semin Reprod Endocrinol. 1999; 17:349-58. [PubMed: 10851574]

30. Osborne CK. Tamoxifen in the treatment of breast cancer. N Engl J Med. 1998; 339:1609-18. [PubMed: 9828250]

31. Osborne CK, Zhao H, Fuqua SAW. Selective estrogen receptor modulators: Structure, function, and clinical use. J Clin Oncol. 2000; 18:3172-86. [PubMed: 10963646]

32. Powles TJ, Hickish T, Kanis JA, Tidy A, Ashley S. Effect of tamoxifen on bone mineral density measured by dual-energy $\mathrm{x}$-ray absorptiometry in healthy premenopausal and postmenopausal women. J Clin Oncol. 1996; 14:78-84. [PubMed: 8558225]

33. Vehmanen L, Elomaa I, Blomqvist C, Saarto T. Tamoxifen treatment after adjuvant chemotherapy has opposite effects on bone mineral density in premenopausal patients depending on menstrual status. J Clin Oncol. 2006; 24:675-80. [PubMed: 16446340]

34. Krishnan AV, Swami S, Peng L, Wang J, Moreno J, Feldman D. Tissue-selective regulation of aromatase expression by calcitriol: Implications for breast cancer therapy. Endocrinology. 2010; 151:32-42. [PubMed: 19906814]

35. Hadji P, Gnant M, Body JJ, Bundred NJ, Brufsky A, Coleman RE, et al. Cancer treatment-induced bone loss in premenopausal women: A need for therapeutic intervention? Cancer Treat Rev. 2012; 38:798-806. [PubMed: 22429722]

36. Hiscox S, Davies EL, Barrett-Lee P. Aromatase inhibitors in breast cancer. Maturitas. 2009; 63:275-79. [PubMed: 19577386]

37. Eastell R, Adams JE, Coleman RE, Howell A, Hannon RA, Cuzick J, et al. Effect of anastrozole on bone mineral density: 5-year results from the anastrozole, tamoxifen, alone or in combination trial 18233230. J Clin Oncol. 2008; 26:1051-57. [PubMed: 18309940]

38. The Arimidex Tamoxifen Alone or in Combination (ATAC) Trialists' Group. Effect of anastrozole and tamoxifen as adjuvant treatment for early-stage breast cancer: 100-month analysis of the ATAC trial. Lancet Oncol. 2008; 9:45-53. [PubMed: 18083636]

39. Rabaglio M, Sun Z, Price KN, Castiglione-Gertsch M, Hawle H, Thürlimann B, et al. Bone fractures among postmenopausal patients with endocrine-responsive early breast cancer treated with 5 years of letrozole or tamoxifen in the BIG 1-98 trial. Ann Oncol. 2009; 20:1489-98. [PubMed: 19474112]

40. Eastell R, Hannon RA, Cuzick J, Dowsett M, Clack G, Adams JE. Effect of an aromatase inhibitor on bmd and bone turnover markers: 2-year results of the anastrozole, tamoxifen, alone or in combination (ATAC) trial (18233230). J Bone Miner Res. 2006; 21:1215-23. [PubMed: 16869719] 
41. American Society of Clinical Oncology. Clinical practice guidelines: Breast cancer. Retrieved August 20, 2012, from http://www.asco.org/ASCOv2/Practice+\%26+Guidelines/Guidelines/ Clinical+Practice+Guidelines/Breast+Cancer

42. Agency for Healthcare Research and Quality. National guideline clearinghouse. Retrieved September 2, 2011, from http://www.guideline.gov/

43. Body J, Bergmann P, Boonen S, Boutsen Y, Devogelaer J, Goemaere S, et al. Management of cancer treatment-induced bone loss in early breast and prostate cancer - a consensus paper of the Belgian Bone Club. Osteoporos Int. 2007; 18:1439-50. [PubMed: 17690930]

44. Hillner BE, Ingle JN, Chlebowski RT, Gralow J, Yee GC, Janjan NA, et al. American society of clinical oncology 2003 update on the role of bisphosphonates and bone health issues in women with breast cancer. J Clin Oncol. 2003; 21:4042-57. [PubMed: 12963702]

45. Rizzoli R, Body J, De Censi A, Reginster J, Piscitelli P, Brandi M. Guidance for the prevention of bone loss and fractures in postmenopausal women treated with aromatase inhibitors for breast cancer: An ESCEO position paper. Osteoporos Int. 2012 DOI:10.1007/s00198-011-1870-0: 1-10.

46. Reid DM, Doughty J, Eastell R, Heys SD, Howell A, McCloskey EV, et al. Guidance for the management of breast cancer treatment-induced bone loss: A consensus position statement from a UK expert group. Cancer Treat Rev. 2008; 34(Supplement 1):S3-S18. [PubMed: 18515009]

47. Hadji P, Aapro MS, Body JJ, Bundred NJ, Brufsky A, Coleman RE, et al. Management of aromatase inhibitor-associated bone loss in postmenopausal women with breast cancer: Practical guidance for prevention and treatment. Ann Oncol. 2011; 22:2546-55. [PubMed: 21415233]

48. BreastCancer org. Retrieved August 15, 2012, from http://www.breastcancer.org

49. Hartsock, MA., editor. Living Beyond Breast Cancer. 1. 2010. Guide to understanding bone health; p. 1-29.

50. Susan, G. Komen for the Cure. Sep 11. 2012 from http://ww5.komen.org/

51. Young Survival Coalition. Taking care of them bones. Living your best: Quality of life. Retrieved September 11, 2012, from http://www.youngsurvival.org/breast-cancer-in-young-women/livingwith-breast-cancer/quality-of-life\#null

52. Llombart A, Frassoldati A, Paija O, Sleeboom HP, Jerusalem G, Mebis J, et al. Immediate administration of zoledronic acid reduces aromatase inhibitor-associated bone loss in postmenopausal women with early breast cancer: 12-month analysis of the E-ZO-FAST trial. Clin Breast Cancer. 2012; 12:40-48. [PubMed: 22014381]

53. Shapiro CL, Manola J, Leboff M. Ovarian failure after adjuvant chemotherapy is associated with rapid bone loss in women with early-stage breast cancer. J Clin Oncol. 2001; 19:3306-11. [PubMed: 11454877]

54. Waltman N, Twiss J, Ott C, Gross G, Lindsey A, Moore T, et al. The effect of weight training on bone mineral density and bone turnover in postmenopausal breast cancer survivors with bone loss: A 24-month randomized controlled trial. Osteoporos Int. 2010; 21:1361-69. [PubMed: 19802506]

55. Cohen A, Fleischer JB, Johnson MK, Brown IN, Joe AK, Hershman DL, et al. Prevention of bone loss after withdrawal of tamoxifen. Endocr Pract. 2008; 14:162-67. [PubMed: 18308653]

56. Kim J, Ahn J-H, Jung K, Kim S-B, Kim H, Lee K-S, et al. Zoledronic acid prevents bone loss in premenopausal women with early breast cancer undergoing adjuvant chemotherapy: A phase iii trial of the korean cancer study group (KCSG-BR06-01). Breast Cancer Res Treat. 2011; 125:99106. [PubMed: 20922564]

57. Shapiro CL, Halabi S, Hars V, Archer L, Weckstein D, Kirshner J, et al. Zoledronic acid preserves bone mineral density in premenopausal women who develop ovarian failure due to adjuvant chemotherapy: Final results from calgb trial 79809. Eur J Cancer. 2011; 47:683-89. [PubMed: 21324674]

58. Hershman DL, McMahon DJ, Crew KD, Cremers S, Irani D, Cucchiara G, et al. Zoledronic acid prevents bone loss in premenopausal women undergoing adjuvant chemotherapy for early-stage breast cancer. J Clin Oncol. 2008; 26:4739-45. [PubMed: 18711172]

59. Hershman DL, McMahon DJ, Crew KD, Shao T, Cremers S, Brafman L, et al. Prevention of bone loss by zoledronic acid in premenopausal women undergoing adjuvant chemotherapy persist up to one year following discontinuing treatment. J Clin Endocrinol Metab. 2010; 95:559-66. [PubMed: 20022990] 
60. Hines SL, Mincey BA, Sloan JA, Thomas SP, Chottiner E, Loprinzi CL, et al. Phase iii randomized, placebo-controlled, double-blind trial of risedronate for the prevention of bone loss in premenopausal women undergoing chemotherapy for primary breast cancer. J Clin Oncol. 2009; 27:1047-53. [PubMed: 19075260]

61. Fuleihan GE-H, Salamoun M, Mourad YA, Chehal A, Salem Z, Mahfoud Z, et al. Pamidronate in the prevention of chemotherapy-induced bone loss in premenopausal women with breast cancer: A randomized controlled trial. J Clin Endocrinol Metab. 2005; 90:3209-14. [PubMed: 15769994]

62. Prieto-Alhambra D, Servitja S, Javaid M, Garrigós L, Arden N, Cooper C, et al. Vitamin D threshold to prevent aromatase inhibitor-related bone loss: The B-ABLE prospective cohort study. Breast Cancer Res Treat. 2012; 133:1159-67. [PubMed: 22434523]

63. Sergi G, Pintore G, Falci C, Veronese N, Berton L, Perissinotto E, et al. Preventive effect of risedronate on bone loss and frailty fractures in elderly women treated with anastrozole for early breast cancer. J Bone Miner Metab. 2012; 30:461-67. [PubMed: 22160398]

64. Safra T, Bernstein-Molho R, Greenberg J, Pelles-Avraham S, Stephansky I, Sarid D, et al. The protective effect of zoledronic acid on bone loss in postmenopausal women with early breast cancer treated with sequential tamoxifen and letrozole: A prospective, randomized, phase II trial. Oncology. 2011:81.

65. Rastelli A, Taylor M, Gao F, Armamento-Villareal R, Jamalabadi-Majidi S, Napoli N, et al. Vitamin D and aromatase inhibitor-induced musculoskeletal symptoms (AIMSS): A phase II, double-blind, placebo-controlled, randomized trial. Breast Cancer Res Treat. 2011; 129:107-16. [PubMed: 21691817]

66. Markopoulos C, Tzoracoleftherakis E, Polychronis A, Venizelos B, Dafni U, Xepapadakis G, et al. Management of anastrozole-induced bone loss in breast cancer patients with oral risedronate: Results from the ARBI prospective clinical trial. Breast Cancer Res. 2010; 12:1-12.

67. Van Poznak C, Hannon RA, Mackey JR, Campone M, Apffelstaedt JP, Clack G, et al. Prevention of aromatase inhibitor-induced bone loss using risedronate: The SABRE trial. J Clin Oncol. 2010; 28:967-75. [PubMed: 20065185]

68. Ellis GK, Bone HG, Chlebowski R, Paul D, Spadafora S, Smith J, et al. Randomized trial of denosumab in patients receiving adjuvant aromatase inhibitors for nonmetastatic breast cancer. $\mathrm{J}$ Clin Oncol. 2008; 26:4875-82. [PubMed: 18725648]

69. Greenspan SL, Brufsky A, Lembersky BC, Bhattacharya R, Vujevich KT, Perera S, et al. Risedronate prevents bone loss in breast cancer survivors: A 2-year, randomized, double-blind, placebo-controlled clinical trial. J Clin Oncol. 2008; 26:2644-52. [PubMed: 18427147]

70. Lester JE, Dodwell D, Purohit OP, Gutcher SA, Ellis SP, Thorpe R, et al. Prevention of anastrozole-induced bone loss with monthly oral ibandronate during adjuvant aromatase inhibitor therapy for breast cancer. Clin Cancer Res. 2008; 14:6336-42. [PubMed: 18829518]

71. Sawka AM, Ioannidis G, Papaioannou A, Thabane L, Olszynski WP, Brown JP, et al. Are oral bisphosphonates effective in improving lumbar bone mineral density in breast cancer survivors with osteopenia or osteoporosis? J Obstet Gynaecol Can. 2005; 27:759-64. [PubMed: 16287007]

72. Roger VL, Go AS, Lloyd-Jones DM, Benjamin EJ, Berry JD, Borden WB, et al. Heart disease and stroke statistics-2012 update. Circulation. 2012; 125:e2-e220. [PubMed: 22179539]

73. Patnaik J, Byers T, DiGuiseppi C, Dabelea D, Denberg T. Cardiovascular disease competes with breast cancer as the leading cause of death for older females diagnosed with breast cancer: A retrospective cohort study. Breast Cancer Res. 2011; 13:R64. [PubMed: 21689398]

74. Wellons M, Ouyang P, Schreiner PJ, Herrington DM, Vaidya D. Early menopause predicts future coronary heart disease and stroke: The multi-ethnic study of atherosclerosis. Menopause. 2012; 19:1081-87. [PubMed: 22692332]

75. Schmitz KH, Prosnitz RG, Schwartz AL, Carver JR. Prospective surveillance and management of cardiac toxicity and health in breast cancer survivors. Cancer. 2012; 118:2270-76. [PubMed: 22488701]

76. Yeh ETH, Bickford CL. Cardiovascular complications of cancer therapy: Incidence, pathogenesis, diagnosis, and management. J Am Coll Cardiol. 2009; 53:2231-47. [PubMed: 19520246] 
77. Hernandez RK, Sørensen HT, Pedersen L, Jacobsen J, Lash TL. Tamoxifen treatment and risk of deep venous thrombosis and pulmonary embolism. Cancer. 2009; 115:4442-49. [PubMed: 19569248]

78. Amir E, Seruga B, Niraula S, Carlsson L, Ocaña A. Toxicity of adjuvant endocrine therapy in postmenopausal breast cancer patients: A systematic review and meta-analysis. J Natl Cancer Inst. 2011; 103:1299-309. [PubMed: 21743022]

79. Xiao Q, Murphy RA, Houston DK, Harris TB, Chow W, Park Y. Dietary and supplemental calcium intake and cardiovascular disease mortality: The National Institutes of Health- AARP diet and health study. JAMA Internal Medicine. 2013; 173:639-46. [PubMed: 23381719]

80. Bolland MJ, Grey A, Avenell A, Gamble GD, Reid IR. Calcium supplements with or without vitamin D and risk of cardiovascular events: Reanalysis of the women's health initiative limited access dataset and meta-analysis. Br Med J. 2011:342.10.1136/bmj.d2040

81. Li K, Kaaks R, Linseisen J, Rohrmann S. Associations of dietary calcium intake and calcium supplementation with myocardial infarction and stroke risk and overall cardiovascular mortality in the Heidelberg cohort of the European Prospective Investigation into Cancer and nutrition study (EPIC-Heidelberg). Heart. 2012; 98:920-25. [PubMed: 22626900]

82. Bolland MJ, Barber PA, Doughty RN, Mason B, Horne A, Ames R, et al. Vascular events in healthy older women receiving calcium supplementation: Randomised controlled trial. BMJ. 2008; 336:262-66. [PubMed: 18198394]

83. Michaëlsson K, Melhus H, Lemming EW, Wolk A, Byberg L. Long term calcium intake and rates of all cause and cardiovascular mortality: Community based prospective longitudinal cohort study. BMJ. 2013; 34610.1136/bmj.f228

84. Lewis JR, Calver J, Zhu K, Flicker L, Prince RL. Calcium supplementation and the risks of atherosclerotic vascular disease in older women: Results of a 5-year RCT and a 4.5-year followup. J Bone Miner Res. 2011; 26:35-41. [PubMed: 20614474]

85. Manson JE, Allison MA, Carr JJ, Langer RD, Cochrane BB, Hendrix SL, et al. Calcium/vitamin D supplementation and coronary artery calcification in the women's health initiative. Menopause. 2010; 17:683-91. [PubMed: 20551849]

86. Bolland MJ, Avenell A, Baron JA, Grey A, MacLennan GS, Gamble GD, et al. Effect of calcium supplements on risk of myocardial infarction and cardiovascular events: Meta-analysis. Br Med J. 2010; 34110.1136/bmj.c3691

87. Samelson EJ, Booth SL, Fox CS, Tucker KL, Wang TJ, Hoffmann U, et al. Calcium intake is not associated with increased coronary artery calcification: The Framingham study. Am J Clin Nutr. 2012; 96:1274-80. [PubMed: 23134889]

88. Heine GH, Nangaku M, Fliser D. Calcium and phosphate impact cardiovascular risk. Eur Heart J. 2013; 34:1112-21. [PubMed: 23109644]

89. Block GA, Spiegel DM, Ehrlich J, Mehta R, Lindbergh J, Dreisbach A, et al. Effects of sevelamer and calcium on coronary artery calcification in patients new to hemodialysis. Kidney Int. 2005; 68:1815-24. [PubMed: 16164659]

90. Chertow GM, Burke SK, Raggi P. Sevelamer attenuates the progression of coronary and aortic calcification in hemodialysis patients. Kidney Int. 2002; 62:245-52. [PubMed: 12081584]

91. Hunt CD, Johnson LK. Calcium requirements: New estimations for men and women by crosssectional statistical analyses of calcium balance data from metabolic studies. Am J Clin Nutr. 2007; 86:1054-63. [PubMed: 17921384]

92. Wang L, Manson JE, Sesso HD. Calcium intake and risk of cardiovascular disease: A review of prospective studies and randomized clinical trials. Am J Cardiovasc Drugs. 2012; 12:105-16. [PubMed: 22283597]

93. Perez EA, Josse RG, Pritchard KI, Ingle JN, Martino S, Findlay BP, et al. Effect of letrozole versus placebo on bone mineral density in women with primary breast cancer completing 5 or more years of adjuvant tamoxifen: A companion study to NCIC CTG MA.17. J Clin Oncol. 2006; 24:362935. [PubMed: 16822845]

94. Straub DA. Calcium supplementation in clinical practice: A review of forms, doses, and indications. Nutr Clin Pract. 2007; 22:286-96. [PubMed: 17507729] 
95. Heaney RP. The importance of calcium intake for lifelong skeletal health. Calcif Tissue Int. 2002; 70:70-73. [PubMed: 11870410]

96. Wang L, Manson JE, Song Y, Sesso HD. Systematic review: Vitamin D and calcium supplementation in prevention of cardiovascular events. Ann Intern Med. 2010; 152:315-23. [PubMed: 20194238]

97. Brøndum-Jacobsen P, Benn M, Jensen GB, Nordestgaard BG. 25-hydroxyvitamin D levels and risk of ischemic heart disease, myocardial infarction, and early death. Arterioscler Thromb Vasc Biol. 2012; 32:2794-802. [PubMed: 22936341]

98. Wang TJ, Pencina MJ, Booth SL, Jacques PF, Ingelsson E, Lanier K, et al. Vitamin D deficiency and risk of cardiovascular disease. Circulation. 2008; 117:503-11. [PubMed: 18180395]

99. Vacek JL, Vanga SR, Good M, Lai SM, Lakkireddy D, Howard PA. Vitamin D deficiency and supplementation and relation to cardiovascular health. Am J Cardiol. 2012; 109:359-63. [PubMed: 22071212]

100. Dawson-Hughes B, Dallal GE, Krall EA, Sadowski L, Sahyoun N, Tannenbaum S. A controlled trial of the effect of calcium supplementation on bone density in postmenopausal women. $\mathrm{N}$ Engl J Med. 1990; 323:878-83. [PubMed: 2203964]

101. Dawson-Hughes B, Harris SS, Krall EA, Dallal GE. Effect of calcium and vitamin D supplementation on bone density in men and women 65 years of age or older. N Engl J Med. 1997; 337:670-76. [PubMed: 9278463]

102. Reid IR, Ames RW, Evans MC, Gamble GD, Sharpe SJ. Effect of calcium supplementation on bone loss in postmenopausal women. N Engl J Med. 1993; 328:460-64. [PubMed: 8421475]

103. Aloia JF, Chen D-G, Yeh JK, Chen H. Serum vitamin D metabolites and intestinal calcium absorption efficiency in women. Am J Clin Nutr. 2010; 92:835-40. [PubMed: 20660223]

104. Riihimäki M, Thomsen H, Brandt A, Sundquist J, Hemminki K. Death causes in breast cancer patients. Ann Oncol. 2012; 23:604-10. [PubMed: 21586686]

\section{Biography}

\section{Biography of corresponding author:}

Gary G Schwartz, PhD, MPH, PhD is Associate Professor of Cancer Biology and Epidemiology and Prevention at Wake Forest School of Medicine. He has contributed to studies in basic science, epidemiology, and clinical trials in the area of calcium/vitamin D and cancer. 


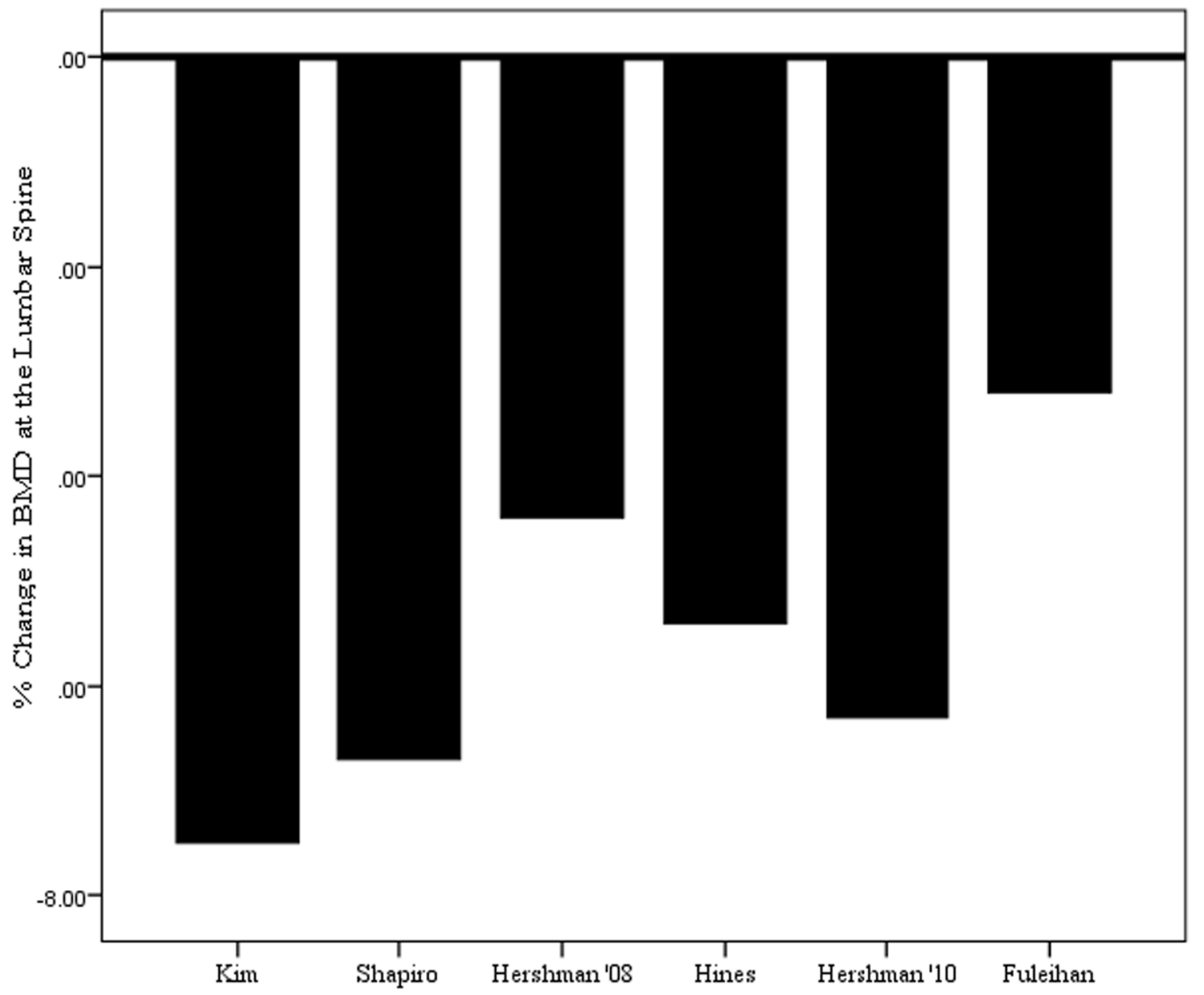

(a) Premenopausal women 


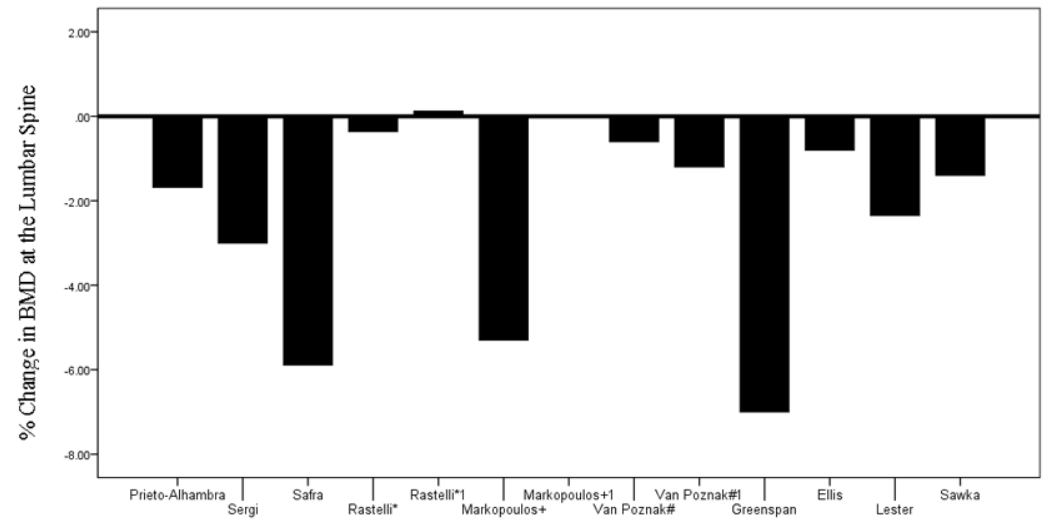

(b) Postmenopausal women

Rastelli - Two different groups in the same trial: * = Placebo group; $* 1=$ Additional vitamin $\mathrm{D}$ group

Markopoulos - Groups stratified based on T-score in the same trial: $+=\mathrm{T}>-1$ group; $+1=-2<\mathrm{T}<-1$ group

Van Poznak - In the same trial, groups stratified based on an astrozole and/or placebo: \# anastrozole only, \#1 = anastrozole+placebo

Figure 1.

Percent change in bone mineral density at the lumbar spine in (a) premenopausal and (b) postmenopausal women with breast cancer 


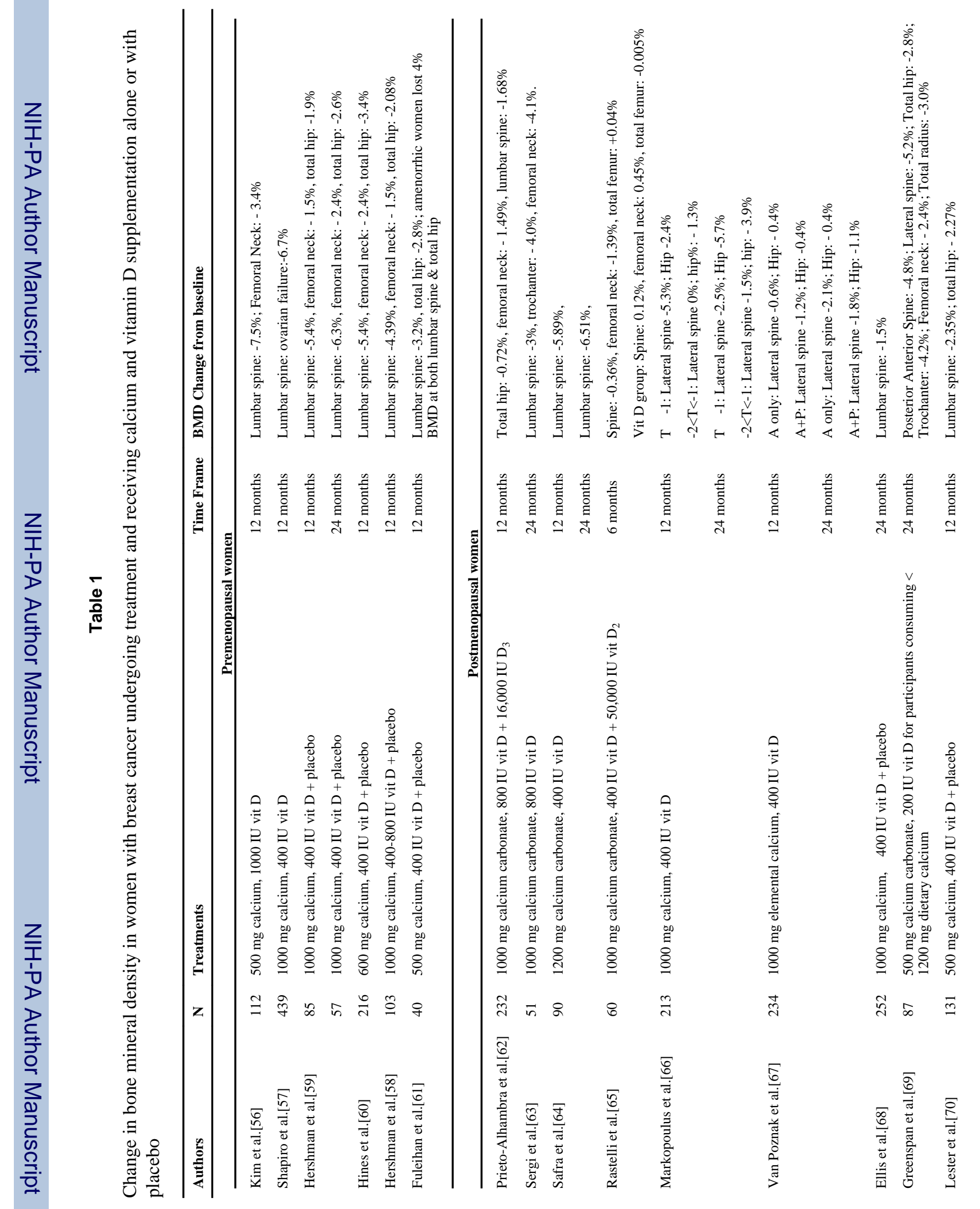




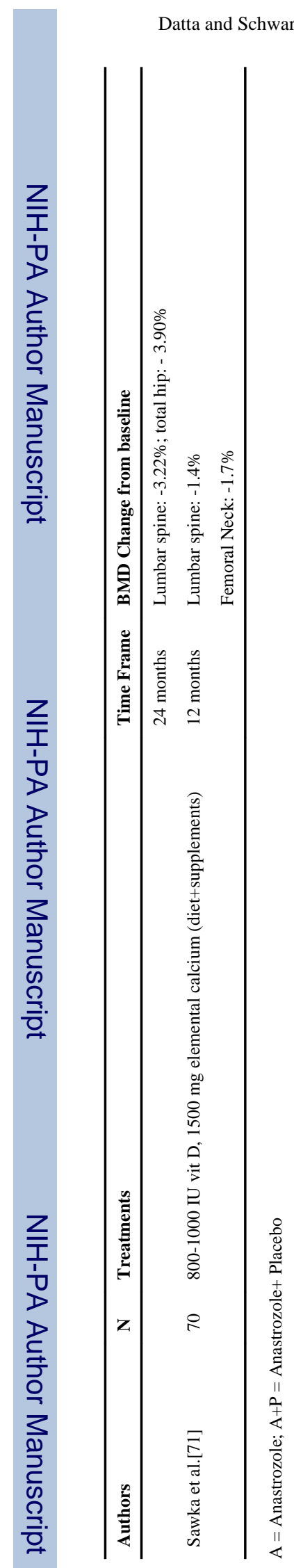

Crit Rev Oncol Hematol. Author manuscript; available in PMC 2014 December 01. 